\title{
The Impact of the Emotional Intelligence of Learners of Turkish as a Foreign Language on Reading Comprehension Skills and Reading Anxiety
}

\author{
Ayşe Ateş \\ Inonu University Turkish Language Learning Research and Application Center, Turkey
}

Copyright $(2019$ by authors, all rights reserved. Authors agree that this article remains permanently open access under the terms of the Creative Commons Attribution License 4.0 International License

\begin{abstract}
In the present study that measured the emotional intelligence of the students who were learning Turkish as a foreign language, the aim was to determine whether the emotional intelligence of the students affected their reading comprehension skills and reading anxiety. Thus, initially, the Schutte Emotional Intelligence Scale was adapted for foreign students after the required approvals were obtained. Then, the correlations between the emotional intelligence of the students and their reading anxiety and reading comprehension skills were investigated. The analysis of the data collected from 138 students attending İnönü University Turkish Language Learning Research and Application Center (TÖMER) demonstrated that the level of emotional intelligence of the students decreased general level reading anxiety levels ( $ß=$ -6.69). It was also concluded that general emotional intelligence level of the students increased their reading comprehension skills ( $\beta=9.079$ ). Furthermore, it was determined the general emotional intelligence scores of female students $(\mathrm{x}=3.389)$ were higher than male students $(\mathrm{x}=3.181)(\mathrm{t}=2.944 ; \mathrm{p}=0.004<0.05)$. As a result, emotional intelligence of the foreign language learning students effects on the reading comprehension skills and the reading anxiety.
\end{abstract}

Keywords Emotional Intelligence, Reading Comprehension Skills, Reading Anxiety

\section{Introduction}

In Turkish Dictionary, intelligence was defined as “overall thinking, reasoning, perception of objective reality, judgment, and conclusion abilities of humans, mental faculty, astuteness and acumen.” Although intelligence is associated with the concept of achievement in individuals' perception, several studies reported that it could be associated with various concepts. On the other hand, it could be argued that emotional intelligence is a combination of emotion and intelligence. That is, the ability to manage people is emotional intelligence. Emotional intelligence is a set of skills that include the differences between individuals' ability to perceive and recognize emotions. In other words, emotional intelligence includes the abilities to perceive and express emotions, to assimilate emotion into thought, to understand and reason using emotions, and to regulate the emotions of oneself and others (Mayer and Salovey, 1997) It is a set of non-cognitive capacities, competences and skills that affect the skills of coping with environmental needs and pressures (Bar-On, 1997). Emotional intelligence is the ability to self-control, perseverance and self-motivation, and formerly the same skill set represented by emotional intelligence was called the character (Goleman, 1995). Rastegar and Memarpour, (2009: 700) said that "A consideration of emotion has been traditionally neglected in the context of teaching and teacher education. This has begun to change with the recent research on emotional intelligence (EI). It is highly likely that emotionally intelligent individuals could provide help in how to manage emotions to less emotionally intelligent individuals. Therefore, the assessment of EI has great relevance for EFL teachers who have to deal with students coming to class with negative feelings about learning a foreign language"

\section{The Aim of the Study}

In the present study where the emotional quotient of the foreign students was measured, it was aimed to determine whether the emotional intelligence of the students had an impact on their reading comprehension skills and reading anxiety. Thus, the research questions included the following: 
1. What are the mean emotional intelligence, reading anxiety and reading comprehension skill scores of the students learning Turkish as a foreign language?

2. What is the effect of the emotional intelligence of the students learning Turkish as a foreign language on their reading anxiety?

3. What is the effect of the emotional intelligence of the students learning Turkish as a foreign language on their reading comprehension levels?

4. Is there a correlation between the emotional intelligence, reading anxiety and reading comprehension skills of the students learning Turkish as a foreign language?

5. Is there a difference between emotional intelligence, reading anxiety and reading comprehension skill scores of the students learning Turkish as a foreign language based on gender, grade, reading habits, and reading frequency variables?

\section{Materials and Methods}

Relational screening method was used in the present study that investigated whether the emotional intelligence of foreign students had an impact on their reading comprehension skills and reading anxiety levels. The relational screening model aims to determine the presence and/or the degree of covariance between two or more variables (Karasar, 2010: 81).

\subsection{Study Group}

In this section, the findings obtained with the analysis of the data collected using the scales are included. Discussions and comments on the findings are presented.

Table 1 demonstrates that 130 (94.2\%) students were Syrian, $1(0.7 \%)$ student was Afghani, 2 (1.4\%) students were Azerbaijani, 4 (2.9\%) 1 (0.7\%) student was Russian based on the nationality variable. Based on the gender variable, 97 (70.3\%) students were female and 41 (29.7\%) were male. Based on the grade variable, $58(42.0 \%)$ wre 11th grade, $10(7.2 \%)$ were 12th grade and $70(50.7 \%)$ were TOMER students. Based on the reading habits variable, 46 (33.3\%) students read regularly and 92 (66.7\%) did not read regularly. Based on reading frequency variable, 13 students (9.4\%) read everyday, 38 (27.5\%) read several times a week, 39 (28.3\%) read several times a month, 48 (34\%) students did not reply to the question. The study group included students attending İnönü University TÖMER during the 2017-2018 academic year.

Table 1. Demographic properties of student

\begin{tabular}{|c|c|c|c|}
\hline Tables & Groups & Frequency(n) & Percentage (\%) \\
\hline \multirow{6}{*}{ Nationality } & Syria & 130 & 94.2 \\
\hline & Afghanistan & 1 & 0.7 \\
\hline & Azerbaijan & 2 & 1.4 \\
\hline & Turkmenistan & 4 & 2.9 \\
\hline & Russia & 1 & 0.7 \\
\hline & Total & 138 & 100.0 \\
\hline \multirow{3}{*}{ Gender } & Female & 97 & 70.3 \\
\hline & Male & 41 & 29.7 \\
\hline & Total & 138 & 100.0 \\
\hline \multirow{4}{*}{ Grade } & 11th Grade & 58 & 42.0 \\
\hline & 12th Grade & 10 & 7.2 \\
\hline & Tömer & 70 & 50.7 \\
\hline & Total & 138 & 100.0 \\
\hline \multirow{3}{*}{ Reading habit } & Yes & 46 & 33.3 \\
\hline & No & 92 & 66.7 \\
\hline & Total & 138 & 100.0 \\
\hline \multirow{5}{*}{ Reading Frequency } & Everyday & 13 & 9.4 \\
\hline & More than once weekly & 38 & 27.5 \\
\hline & More than once monthly & 39 & 28.3 \\
\hline & N/A & 48 & 34.8 \\
\hline & Total & 138 & 100.0 \\
\hline
\end{tabular}




\subsection{Data Collection Instruments}

To measure the reading anxiety levels of the students, a scale developed by Altunkaya and Erdem (2015) was used. The five-point Likert-type scale included 16 items. The reliability of the scale was given as .82 . The scale consists of 3 sub-dimensions. These are: grammar anxiety, reading comprehension anxiety, and reading anxiety.

In order to measure the reading comprehension skill levels of the students, "Turkish as a Foreign Language Reading Comprehension Achievement Test (YDTOBT)," developed for B-level students who learn Turkish as a foreign language, was used. This achievement test, developed by Altunkaya (2016), included 6 true/false and 39 multiple choice questions. The highest possible score is 45 and the lowest score is 0 in the test.

Emotional intelligence scale was another data collection instrument utilized in the study. It was developed by Schutte, Malouff, Hall, Haggerty, Cooper, Golden and Dornheim based on Salovey and Mayer (1990). The Schutte Emotional Intelligence Scale was redeveloped by Austin, Saklofese, Huang and McKenney to include 41 items. Turkish adaptation and analysis of the psychometric properties of the scale were conducted by Tatar, Tok and Saltukoğlu in 2011. The researchers presented the factors proposed in the new form of the scale as three factors that included 41 items. These were defined as Optimism / Mood Regulation, Utilization of Emotions, and Appraisal of Emotions. The new form of the scale included the factors of Optimism / Mood Regulation, Utilization of Emotions, and Appraisal of Emotions. In the five-point Likert-type scale $(1=$ Strongly Disagree and $5=$ Strongly Agree), the lowest possible score is 41 , and the highest possible score is 205.

\subsection{Data Analysis}

The study data were analyzed with SPSS (Statistical Package for Social Sciences) for Windows 22.0 software. Count, percentage, mean, standard deviation were used as descriptive statistics methods in data analysis. t-test was used in the comparison of quantitative continuous data among two independent groups, and one-way ANOVA was used in the comparison of quantitative continuous data among more than two independent groups. Pearson correlation and regression analysis were conducted on the continuous variables in the study.

The construct validity of the scale was analyzed with confirmatory factor analysis on pilot data collected from 240 foreign students who were learning Turkish as a foreign language. 121 students were attending İnönü University TÖMER during the 2017-2018 academic year. 58 students were 11th grade students who attended a camp on a voluntary basis and 8 were $10^{\text {th }}$ grade students attending the same camp. 61 students were attending İnönü University TÖMER during the 2018-2019 academic year.

It was determined in the pilot scheme that the reliability of the scale was Alpha $=0.856$. Three-factor construct confirmatory factor analysis findings demonstrated that common fitness indices were as follows: $\chi 2 / \mathrm{sd}=1.90$; GFI (Goodness of Fit Index) $=.90$; AGFI (Adjusted Goodness Of Fit Index) = 90; CFI (Confirmatory Fit Index) = 90; RMSEA (Root Mean Square Error of Approximation) $=.06$; RMR (Root Mean Square Residual) $=.07$. The analysis results demonstrated that the fitness statistics calculated by confirmatory factor analysis were consistent with the explained factors. It was determined that the reliability coefficient for the scale was high (alpha = $0.863)$.

In the present study, it was found that the Cronbach's Alpha reliability coefficient for the reading anxiety scale was high (Alpha $=0.932)$.

In the present study, the reliability for the reading comprehension skill achievement test was determined as high: KR20 = 0.922; KR21 = 0.906; Split-Half (odd-even) Correlation $=0.884$; Spearman-Brown Prophecy $=0.939$; Cronbach's Alpha $=0.923$.

\section{Results}

The findings obtained with the analysis of the data collected using the scales to obtain the solution of the research problem are included in this section. Explanations and comments on the findings are presented below.

The mean emotional intelligence, reading anxiety and reading comprehension skill scores of the students learning Turkish as a foreign language were included in a research sub-problem. Thus, the mean emotional intelligence, reading anxiety and reading comprehension skill scores of the students are presented in Table 2.

Table 1. The mean emotional intelligence, reading anxiety and reading comprehension skill scores

\begin{tabular}{|c|c|c|c|c|c|c|}
\hline & $\mathrm{N}$ & Mean & Sd & Min. & Max. & Range \\
\hline Optimism mood regulation & 138 & 3.476 & 0.539 & 1.710 & 4.810 & $1-5$ \\
\hline Appraisal of the emotions & 138 & 3.227 & 0.554 & 1.770 & 4.770 & $1-5$ \\
\hline Utilization of the emotions & 138 & 3.066 & 0.612 & 1.290 & 4.430 & $1-5$ \\
\hline General Emotional Intelligence & 138 & 3.327 & 0.388 & 2.540 & 4.610 & $1-5$ \\
\hline General Reading Anxiety & 138 & 40.442 & 15.021 & 16.000 & 74.000 & $16-80$ \\
\hline Reading Comprehension Skill & 138 & 32.370 & 8.950 & 8.000 & 43.000 & $0-45$ \\
\hline
\end{tabular}


Table 2 demonstrates that the mean optimism mood regulation score of the participating students was $3.476 \pm$ 0.539 ), the mean appraisal of emotions score was $3.227 \pm$ $0.554)$, the mean utilization of emotions score was $3.066 \pm$ 0.612 , general emotional intelligence mean score was $3.327 \pm 0.388$ ), general reading anxiety mean score was $40.442 \pm 15.021$, and the mean reading comprehension skill score was $32.370 \pm 8.950$.

The correlations between the emotional intelligence, reading anxiety and reading comprehension skills of the students learning Turkish as a foreign language were included in a research sub-problem. Thus, Pearson correlation and regression analysis was conducted on the continuous variables in the study.

Table 3 demonstrated that there was a weak positive correlation between utilization of emotions and appraisal of emotions ( $r=0.4 ; p=0.000<0.05)$.

There was a high positive correlation between general emotional intelligence and optimism mood regulation scores $(r=0.796 ; p=0.000<0.05)$. There was a significant positive correlation between general emotional intelligence and appraisal of emotions scores $(\mathrm{r}=0.669 ; \mathrm{p}=0.000$ $<0.05$ ). There was a weak positive correlation between general emotional intelligence and utilization of emotions scores $(r=0.489 ; p=0,000<0.05)$. Thus, it can be suggested that there were significant correlations between emotional intelligence and the sub-dimensions of the emotional intelligence scale.

There was a very weak negative and significant correlation between general reading anxiety and appraisal of emotions scores $(r=-0.167 ; p=0.050<0.05)$. Appraisal of emotions is only possible when the emotions are recognized and identified. Thus, it would be accurate to suggest that the students who recognized their feelings better exhibited lower reading anxiety. There was a very weak negative and significant correlation between general reading anxiety and general emotional intelligence scores $(r=-0.178 ; p=0.037<0.05)$. It can be suggested that as the students' emotional intelligence increased, their reading anxiety levels decreased.

There was a weak, positive and significant correlation between reading comprehension skills and optimism mood regulation scores $(r=0.406$; $p=0.000<0.05)$. There was a very weak positive and significant correlation between reading comprehension skills and utilization of emotions scores $(r=0.209 ; p=0.014<0.05)$. The significant correlations between reading comprehension skills and sub-dimensions of emotional intelligence were noteworthy. There was a weak positive and significant correlation between the reading comprehension skills and emotional intelligence scores $(r=0.394 ; p=0,000<0.05)$. It could be suggested that students' reading comprehension skills increased with their emotional intelligence. The correlations among the other variables were not statistically significant ( $p>0.05)$.

The sub-problems "What is the effect of the emotional intelligence of the students learning Turkish as a foreign language on their reading anxiety?" and "What is the effect of the emotional intelligence of the students learning Turkish as a foreign language on their reading comprehension levels?” were scrutinized in Table 4.

Table 2. Analysis of the correlation between emotional intelligence, reading anxiety and reading comprehension skills

\begin{tabular}{|c|c|c|c|c|c|c|c|}
\hline & & $\begin{array}{l}\text { Optimism/Mood } \\
\text { Regulation }\end{array}$ & $\begin{array}{l}\text { Appraisal of } \\
\text { Emotions }\end{array}$ & $\begin{array}{l}\text { Utilization of } \\
\text { Emotions }\end{array}$ & $\begin{array}{l}\text { General Emotional } \\
\text { Intelligence }\end{array}$ & $\begin{array}{l}\text { General } \\
\text { Reading } \\
\text { Anxiety }\end{array}$ & $\begin{array}{c}\text { Reading } \\
\text { Comprehension } \\
\text { Skill } \\
\end{array}$ \\
\hline \multirow{2}{*}{$\begin{array}{l}\text { Optimism/Mood } \\
\text { Regulation }\end{array}$} & $\mathrm{r}$ & 1.000 & & & & & \\
\hline & $\mathrm{p}$ & 0.000 & & & & & \\
\hline \multirow{2}{*}{$\begin{array}{l}\text { Appraisal of } \\
\text { Emotions }\end{array}$} & r & 0.154 & 1.000 & & & & \\
\hline & $\mathrm{p}$ & 0.071 & 0.000 & & & & \\
\hline \multirow{2}{*}{$\begin{array}{l}\text { Utilization of } \\
\text { Emotions }\end{array}$} & r & 0.055 & $0.400 * *$ & 1.000 & & & \\
\hline & $\mathrm{p}$ & 0.520 & 0.000 & 0.000 & & & \\
\hline \multirow{2}{*}{$\begin{array}{l}\text { General Emotional } \\
\text { Intelligence }\end{array}$} & $\mathrm{r}$ & $0.796^{* *}$ & $0.669 * *$ & $0.489 * *$ & 1.000 & & \\
\hline & $\mathrm{p}$ & 0.000 & 0.000 & 0.000 & 0.000 & & \\
\hline \multirow{2}{*}{$\begin{array}{l}\text { General Reading } \\
\text { Anxiety }\end{array}$} & $\mathrm{r}$ & -0.151 & -0.167 & 0.019 & $-0.178^{*}$ & 1.000 & \\
\hline & $\mathrm{p}$ & 0.077 & 0.050 & 0.821 & 0.037 & 0.000 & \\
\hline \multirow{2}{*}{$\begin{array}{c}\text { Reading } \\
\text { Comprehension Skill }\end{array}$} & $\mathrm{r}$ & $0.406^{* *}$ & 0.108 & $0.209 *$ & $0.394^{* *}$ & -0.060 & 1.000 \\
\hline & $\mathrm{p}$ & 0.000 & 0.206 & 0.014 & 0.000 & 0.488 & 0.000 \\
\hline
\end{tabular}

$*<0,05 ; * *<0,01$ 
Table 3. The effect of emotional intelligence on reading comprehension skills

\begin{tabular}{|c|c|c|c|c|c|c|c|}
\hline Dependent Variable & Independent Variable & $ß$ & $\mathrm{t}$ & $\mathrm{p}$ & $\mathrm{F}$ & Model (p) & $\mathrm{R}^{2}$ \\
\hline \multirow{2}{*}{ General Reading Anxiety } & Constant & 63.295 & 5.79 & 0.000 & \multirow{2}{*}{4.43} & \multirow{2}{*}{0.037} & \multirow{2}{*}{0.024} \\
\hline & General Emotional Intelligence & -6.869 & -2.105 & 0.037 & & & \\
\hline \multirow{2}{*}{ Reading Comprehension Skill } & Constant & 2.163 & 0.356 & 0.723 & \multirow{2}{*}{24.99} & \multirow{2}{*}{0.000} & \multirow{2}{*}{0.149} \\
\hline & General Emotional Intelligence & 9.079 & 4.999 & 0 & & & \\
\hline \multirow{4}{*}{ Reading Comprehension Skill } & Constant & 2.040 & 0.340 & 0.734 & \multirow{4}{*}{11.218} & \multirow{4}{*}{0.000} & \multirow{4}{*}{0.183} \\
\hline & Optimism Mood Regulation & 6.638 & 5.117 & 0.000 & & & \\
\hline & Appraisal of emotions & -0.541 & -0.393 & 0.695 & & & \\
\hline & Utilization of emotions & 2.936 & 2.381 & 0.019 & & & \\
\hline \multirow{4}{*}{ General Reading Anxiety } & Constant & 61.591 & 5.621 & 0.000 & \multirow{4}{*}{3.906} & \multirow{4}{*}{0.049} & \multirow{4}{*}{0.031} \\
\hline & Optimism Mood Regulation & -3.551 & -1.498 & 0.136 & & & \\
\hline & Appraisal of emotions & -5.103 & -2.030 & 0.044 & & & \\
\hline & Utilization of emotions & 2.499 & 1.109 & 0.269 & & & \\
\hline
\end{tabular}

Table 4 demonstrated that the regression analysis conducted to determine the causality between general emotional intelligence and general reading anxiety was significant ( $F=4,430 ; p=0,037<0.05)$. It was observed that general emotional intelligence variable weakly explained the general reading anxiety level $\left(\mathrm{R}^{2}=0.024\right)$. The general emotional intelligence level of the students decreased the general level of reading anxiety $(\beta=-6.869)$.

The regression analysis conducted to determine the causality between general emotional intelligence and reading comprehension skill was significant $(F=24,990$; $\mathrm{p}=0,000<0.05$ ). It was observed that general emotional intelligence variable weakly explained the reading comprehension skills $\left(R^{2}=0.149\right)$. The general emotional intelligence level of the students increased the general level of the reading comprehension skills ( $(=9.079)$.

The regression analysis conducted to determine the causality between optimism mood regulation, appraisal of emotions and reading comprehension skills was significant $(F=11,218 ; p=0,000<0.05)$. It was observed that optimism mood regulation, appraisal of emotions and reading comprehension skills weakly explained the reading comprehension skills $\left(\mathrm{R}^{2}=0,183\right)$. The optimism mood regulation level of the students increased the reading comprehension skill levels $(~(\beta=6.638)$. The appraisal of emotions level of the students did not affect their reading comprehension skill levels ( $p=0.695>0.05)$. The utilization of emotions level of the students increased their reading comprehension skill levels $(~(B=2.936)$.

The regression analysis conducted to determine the causality between optimism mood regulation, appraisal of emotions, utilization of emotions and general reading anxiety was significant $(\mathrm{F}=3,906 ; \mathrm{p}=0,049<0.05)$. It was observed that optimism mood regulation, appraisal of emotions and utilization of emotions weakly explained the general reading anxiety levels $R^{2}=0.031$. The optimism mood regulation level of the students did not affect their reading anxiety levels $(\mathrm{p}=0.136>0.05)$. The appraisal of emotions level of the students decreased their general reading anxiety levels ( $\beta=-5.103$ ). The utilization of emotions level of the students did not affect their general reading anxiety levels $(\mathrm{p}=0.269>0.05)$.

A comparison was conducted in Table 5 for the research question "Is there a difference between emotional intelligence, reading anxiety and reading comprehension skill scores of the students learning Turkish as a foreign language based on gender, grade, reading habits, and reading frequency variables?”

It was determined that the general emotional intelligence scores of female students $(x=3.389)$ were higher when compared to the general emotional intelligence scores of male students $(\mathrm{x}=3.181)(\mathrm{t}=2.944 ; \mathrm{p}=0.004<0.05)$. There was no significant difference between the general reading anxiety and reading comprehension skills scores of the students based on gender variable ( $p>0.05)$.

It was determined that reading comprehension scores of 11th and 12th graders $(x=36.397)$ were higher when compared to reading comprehension scores of TÖMER students $(x=28.457)(t=5.797 ; p=0<0.05)$. There was no significant difference between the general emotional intelligence and general reading anxiety scores of the students based on the grade variable ( $p>0.05)$.

It was determined that the general emotional intelligence scores of the students with a reading habit $(\mathrm{x}=3.202)$ were lower when compared to those without a reading habit $(\mathrm{x}=3.390) \quad(\mathrm{t}=-2.739 ; \mathrm{p}=0.007<0.05)$. There was no significant difference between general reading anxiety and reading comprehension scores of the students based on the reading habit variable ( $p>0.05)$.

There was no significant difference between general emotional intelligence, general reading anxiety and reading comprehension scores of the students based on the reading frequency variable $(\mathrm{p}>0.05)$. 
The Impact of the Emotional Intelligence of Learners of Turkish

as a Foreign Language on Reading Comprehension Skills and Reading Anxiety

Table 4. Comparison of emotional intelligence, reading anxiety and reading comprehension skills based on descriptive attributes

\begin{tabular}{|c|c|c|c|c|}
\hline Demographics & $\mathrm{n}$ & $\begin{array}{l}\text { General Emotional } \\
\text { Intelligence }\end{array}$ & General Reading Anxiety & $\begin{array}{c}\text { Reading Comprehension } \\
\text { Skill }\end{array}$ \\
\hline Gender & & Mean \pm SD & Mean \pm SD & Mean \pm SD \\
\hline Female & 97 & $3.389 \pm 0.380$ & $41.103 \pm 15.713$ & $32.670 \pm 8.956$ \\
\hline Male & 41 & $3.181 \pm 0.373$ & $38.878 \pm 13.291$ & $31.659 \pm 9.007$ \\
\hline $\mathrm{t}=$ & & 2.944 & 0.794 & 0.605 \\
\hline $\mathrm{p}=$ & & 0.004 & 0.429 & 0.546 \\
\hline Grade & & Ort $\pm S S$ & Ort $\pm S S$ & Ort $\pm S S$ \\
\hline 11 and 12 & 68 & $3.388 \pm 0.398$ & $42.897 \pm 14.744$ & $36.397 \pm 6.227$ \\
\hline Tömer & 70 & $3.268 \pm 0.372$ & $38.057 \pm 15.007$ & $28.457 \pm 9.480$ \\
\hline $\mathrm{t}=$ & & 1.832 & 1.911 & 5.797 \\
\hline $\mathrm{p}=$ & & 0.069 & 0.058 & 0.000 \\
\hline Reading habit & & Ort $\pm S S$ & Ort $\pm S S$ & Ort $\pm S S$ \\
\hline Yes & 46 & $3.202 \pm 0.399$ & $40.826 \pm 15.679$ & $30.696 \pm 9.505$ \\
\hline No & 92 & $3.390 \pm 0.370$ & $40.250 \pm 14.765$ & $33.207 \pm 8.590$ \\
\hline $\mathrm{t}=$ & & -2.739 & 0.212 & -1.562 \\
\hline $\mathrm{p}=$ & & 0.007 & 0.833 & 0.121 \\
\hline Reading frequency & & Ort $\pm S S$ & Ort \pm SS & Ort $\pm S S$ \\
\hline Everyday & 13 & $3.296 \pm 0.437$ & $36.692 \pm 12.822$ & $30.692 \pm 9.647$ \\
\hline More than once weekly & 38 & $3.213 \pm 0.364$ & $37.132 \pm 13.780$ & $33.605 \pm 7.416$ \\
\hline More than once monthly & 39 & $3.273 \pm 0.361$ & $40.051 \pm 14.347$ & $30.487 \pm 10.445$ \\
\hline $\mathrm{F}=$ & & 0.357 & 0.530 & 1.233 \\
\hline $\mathrm{p}=$ & & 0.701 & 0.590 & 0.296 \\
\hline
\end{tabular}

\section{Discussion}

Based on the overall reading anxiety scores of the students, it could be concluded that they had moderate levels of anxiety. A high score in this reliable and valid scale developed for B-level students who learn Turkish as a second language could suggest high reading anxiety among the students, while a low score could be considered as as a sign of low reading anxiety, and a mean score as a sign of the moderate reading anxiety (Altunkaya, Erdem, 2015).

Tosun (2013) mentioned that several individuals complain that they could not learn English at a desired level in Turkey and hinted that this could be due to the impact of emotional intelligence and its sub-factors on learning. Thus, the above-mentioned study aimed to identify the correlation between emotional intelligence and language learning skills to contribute to the field of English Language Teaching (ELT). In conclusion, it was found that there was no difference between emotional intelligence levels based on gender except for interpersonal emotional intelligence $(t=-3.69, \mathrm{p}<.01)$. Based on the above-mentioned findings, it could be concluded that the general emotional intelligence scores of the female students were higher when compared to the male students. Furthermore, there were significant positive correlations between emotional intelligence and language achievement (GPA) $(\mathrm{r}=.426, \mathrm{p}<.01)$, reading ( $\mathrm{r}$ $=.298, \mathrm{p}<.01)$, listening $(\mathrm{r}=.351, \mathrm{p}<.01)$, writing $(\mathrm{r}$ $=.346, \mathrm{p}<.01)$ and speech $(\mathrm{r}=.299, \mathrm{p}<.01)$ skills. Regression analysis was used to determine the impact of emotional intelligence on language achievement and language skills, and it was determined that emotional intelligence had a strong impact on language achievement $(\mathrm{r} 2=.181, \mathrm{p}<.01)$. These findings were consistent with the present study. There was a weak, positive and significant correlation between reading comprehension skill and emotional intelligence $(r=0.394 ; p=0.000$ $<0.05$ ). It can be suggested that reading comprehension skills of the students improved as their emotional intelligence levels increased. Furthermore, the regression analysis between the two groups was statistically significant. $(\mathrm{F}=24.990 ; \mathrm{p}=0.000<0.05)$.

Nesari, A.J. Karimi and L. Filinezhad N. (2011) conducted a study to determine whether there was a correlation between emotional intelligence and learning foreign language vocabulary with Iranian students and found that there was a significant correlation between 
emotional intelligence and vocabulary learning. Al-Mahrooqi and Balasubramanian (2016) investigated whether the lack of Emotional Intelligence skills was one of the factors that prevented the students' proficiency in English. As a result, it was demonstrated that the lack of Emotional Intelligence affected the student's learning abilities. Based on the above-mentioned findings, it could be concluded that students should possess sufficient reading anxiety and reading comprehension skills. This would help demonstrate the significance of the present study.

A study by Izadi and Nowrouzi (2016) aimed to investigate the effect of antiphony strategies education and emotional intelligence on reading comprehension skills of EFL students. Data analysis demonstrated that all students exhibited superior performances in post-tests, except for low-level readers in the high-emotional-intelligence group, and it was reported that antiphony significantly improved students' reading comprehension skills and the impact of the emotional intelligence was not significant. It was associated with the antiphony strategy education based on the reading comprehension levels of the students. Genç, Kuluşakl1, Aydin (2016) studied the correlation between emotional intelligence and language learning. The study data demonstrated that learning a foreign language was strongly correlated with various dimensions of emotional intelligence.

Shirazi, Nadoushani, (2016) aimed to investigate the correlation between the emotional intelligence of native Persian EFL learners and the expressions used in statements of courtesy. The correlation and regression analysis findings demonstrated that emotional intelligence could not predict courtesy, and the level of education and pragmatic competence could predict the courtesy of EFL learners appreciated in different scenarios. In a study by Alavinia P, Mollahossein H. (2012), the author aimed to determine the correlation between emotional intelligence (and its sub-components) and the use of metacognitive listening strategies by academic EFL learners. Using the Pearson correlation coefficient, the researchers found a significant correlation between the metacognitive listening strategies in emotional intelligence subscales (Intrapersonal, Interpersonal, Adaptability, and general mood) and the use of total emotional intelligence scores and the student scores, with the only exception of stress management. Furthermore, it was found that the correlations between 5 subscales of emotional intelligence and the use of monitoring strategies and interpersonal skills and assessment strategy were significant.

Valizadeh, Alavinia (2013) aimed to investigate the potential correlation between emotional intelligence and listening comprehension performances of Iranian EFL students. They found that there was a strong correlation between listening comprehension performances and emotional intelligence scores of the students. Furthermore, there was a strong negative correlation between listening anxiety and listening comprehension performances. In the present study, regression analysis was conducted to determine the causal relationship between emotional intelligence and reading anxiety $(F=4.430 ; p=0.037$ $<0.05)$. It was fund that the general emotional intelligence levels of the students decreased the general reading anxiety levels ( $\beta=-6,869$ ). Thus, it could be suggested that emotional intelligence had an effect on skill levels.

A study conducted by Valizadeh (2016) aimed to clarify the concept of autonomy among EFL learners and to explain whether their autonomy correlated with their emotional intelligence levels. The results of the statistical analysis revealed that there was a significant correlation between the students' autonomy concepts and their emotional intelligence. In general, the findings revealed that emotional intelligence was an important factor on the readiness of the students to learn autonomously and the teachers could therefore attempt to identify the type of the intelligence of the students before they were trained to be autonomous. Furthermore, similar findings could be expected for the students who learn Turkish as a foreign language. Thus, it would be accurate to determine the types of the intelligence of the students. A study by Ghabanchi and Rastegar (2014) aimed to determine the effects of both IQ and emotional intelligence on reading comprehension skills in Iran. The results demonstrated that the correlation between IQ and reading comprehension was stronger when compared to the correlation between total emotional intelligence and reading comprehension. A minor but significant relationship was found between the reading comprehension scores of the students and certain emotional intelligence subscale scores such as interpersonal skills, innate abilities and stress management. This follows that IQ was a more decisive factor on reading comprehension when compared to emotional intelligence. These findings were consistemt with the present study results. General emotional intelligence level of the students increased their reading comprehension skills $(\Omega=$ 9.079). The optimism/mood regulation level of the students increased their reading comprehension levels ( $(\beta=$ 6.638). The level appraisal of emotions of the students did not affect their reading comprehension skill levels $(\mathrm{p}=$ $0.695>0.05$ ). The level of the use of emotions by the students increased their reading comprehension levels ( $(=$ 2.936).

Ebrahimi, Khoshsima, Zare-Behtash Heydarnejad (2018) conducted an empirical study to control the effect of Emotional Intelligence on Speech Skills. As a result, it was determined that both EQ and speaking skills of students in the experimental group improved significantly, only the speech skills improved in the control group, however the variation was not significant. The study findings could contribute to the knowledge on the impact of EQ on language learning. Koçoğlu (2011) investigated 
the correlation between emotional intelligence and teacher competency with 90 pre-service English language teachers in a university in Turkey. The study demonstrated that Turkish EFL pre-service teachers were more effective in managing the classroom when compared to conducting an entertaining instruction. It was also determined that pre-service teachers received the highest scores in stress tolerance and assertiveness competencies, however the lowest scores were obtained in independence and autonomy in emotional intelligence (EQ). The findings revealed a significant and positive correlation between EQ and pre-service teacher competency. Thus, it could be suggested that emotional intelligence has an impact on every sphere of life.

In their study, Huertaa, Goodsonb, Beigic, Chlup (2017) studied writing anxiety, self-efficacy and emotional intelligence (EI) with a case of a graduate student in a large, intensive research university in the United States. Their findings demonstrated that self-efficacy was a statistically significant major predictor of writing anxiety in the absence of emotional intelligence, however descriptive data demonstrate a moderate correlation between EI and the native language (i.e., whether a student reported English as the native language).

Afshar, Tofighi, Hamazavi, (2016) investigated the correlations between emotional intelligence, learning style, language learning strategy and L2 achievement in Iranian EFL learners in their study. It was found that there was no statistically significant correlation between learning styles and L2 achievement. However, the findings demonstrated that there was a significant correlation between L2 achievement and emotional intelligence and language learning strategy. The multiple regression analysis findings revealed that the use of strategy followed by emotional intelligence was the most powerful predictor of L2 achievement among the study variables. Furthermore, the findings demonstrated that emotional intelligence components were the best predictors of L2 achievement. Based on the above-mentioned findings, it could be suggested that further studies should be conducted on emotional intelligence.

Moafian, and Ghanizadeh (2009) aimed to investigate the relationship between Iranian EFL teachers' emotional intelligence and their self-efficacy in Language Institutes. Data analysis and statistical calculations demonstrated that there is a significant relationship between the teachers' emotional intelligence and their self-efficacy. To investigate which components of emotional intelligence might have more predictive power in predicting teacher's self-efficacy, regression analysis was run. Three subscales of emotional intelligence - emotional self-awareness, interpersonal-relationship, and problem solving - were found to be good predictors of teacher self-efficacy. A study by Shao, Yu and Ji (2013) aimed to investigate the possibility of using literature-based activities to improve the EQ of EFL students and to determine whether there was a correlation between their EQ and writing. The findings demonstrated that the students in the experimental group were significantly higher when compared to those in the TEIQue-ASF control group and that they were able to write in post-tests. There was also a relatively strong positive correlation between EI and writing achievement in the present study and the above-mentioned study is important in this respect. In their study, López and Tun (2017) aimed to understand the factors that motivate and reduce the motivation of the students with low emotional intelligence to participate in speech activities during English lessons. The results demonstrated that male participants experienced a higher number of negative emotions, while females experienced fewer such emotions. However, in comparative terms, females experienced negative emotions, although they often self-experienced these emotions. The findings also demonstrated that there were differences between males and females differ based the way they perceived and experienced the situations and how they regulated the emotions caused by these situations.

As a result, the effect of emotional intelligence on language is obvious when the entire literature is reviewed. In this study, it was measured the emotional intelligence of the students who were learning Turkish as a foreign language, to determine whether the emotional intelligence of the students affected their reading comprehension skills and reading anxiety. It can be thought that studies about emotional intelligence of students may not only affect reading skills, but also their listening, writing and speaking skills. In this respect, their relationship with other skills will shed light on new studies. In addition, this study can be applied to all level students and interdisciplinary approach can be related to other courses.

\section{REFERENCES}

[1] Afshar, H.S., Tofighi S., \& Hamazavi, R. (2016). Iranian EFL learners' emotional intelligence, learning styles, strategy use, and their L2 achievement. Issues in Educational Research, 26(4), 2016.

[2] Alavinia P., Mollahossein H. (2012). On the correlation between Iranian EFL learners' use of metacognitive listening strategies and their emotional intelligence. International Education Studies; Vol. 5, No. 6, 2012.

[3] Al-Mahrooqi, R. Balasubramanian, C. (2016). Emotional intelligence in language instruction in Oman: The missing link? RELC Journal 2016, Vol. 47(2), 145 -160.

[4] Altunkaya, H. (2016). Development of achievement test for comprehension of what was read for those learning Turkish as foreign language. Turkish Studies, Volume 11/3 Winter, p. 113-138.

[5] Altunkaya, H., Erdem, İ. (2015). Improving the reading anxiety scale for learners of Turkish as a foreign language. 
teaching Turkish in the context of theory and practice. Ankara: An1 Publishing, Turkey.

[6] Bar-On, R. (1997). The Emotional Quotient inventory (EQ-I): A Test of Emotional Intelligence. Toronto: Multi-Health Systems, 28.

[7] Ebrahimi, M.R., Khoshsima, H., Zare-Behtash, E., Heydarnejad, T. (2018). Emotional intelligence enhancement impacts on developing speaking skill among EFL learners: an empirical study. International Journal of Instruction. October Vol.11, No.4.

[8] Genç, G., Kuluşaklı, E., Aydın, S. (2016). The relationship between emotional intelligence and productive language skills. The Reading Matrix: An International Online Journal Volume 16, Number 1, April 2016.

[9] Ghabanchi, Z., Rastegar, R. (2014). The correlation of Iq and emotional intelligence with reading comprehension. The Reading Matrix, Volume 14, Number 2, September, 2014.

[10] Goleman, D. (1995). Emotional intelligence. Psychosomatic Medicine, 8(95), 160168.

[11] Huertaa, M., Goodsonb, P., Beigic M., Chlup D. (2017). Graduate students as academic writers: writing anxiety, self-efficacy and emotional intelligence. Higher Education Research \& Development, 36:4, 716-729.

[12] Izadi M., Nowrouzi H. (2016). Reciprocal teaching and emotional intelligence: A study of Iranian EFL learners' reading comprehension. The Reading Matrix: An International Online Journal Volume 16, Number 1, April 2016.

[13] Koçoğlu, Z. (2011). Emotional intelligence and teacher efficacy: a study of Turkish EFL pre-service teachers. Teacher Development, 15:4, 471-484.

[14] López, M. G., \& Bautista Tun, M. (2017). Motivating and demotivating factors for students with low emotional intelligence to participate in speaking activities. Profile Issues in Teachers' Professional Development, 19(2), 151-163.

[15] Mayer, J. D. and Salovey, P. (1997). What is emotional intelligence? emotional development and emotional intelligence: educational implications. New York: Basic Books, 3-34.

[16] Moafian, F., Ghanizadeh A. (2009). The relationship between Iranian EFL teachers' emotional intelligence and their self-efficacy in Language Institutes. System 37 (2009) 708-718.

[17] Nesari, A.J. Karimi, L. Filinezhad N. (2011), On the relationship between emotional intelligence and vocabulary learning of Iranian EFL learners at the intermediate level. Procedia - Social and Behavioral Sciences 28 (2011) 900 903.

[18] Rastegar, M., Memarpour, S. (2009). The relationship between emotional intelligence and self-efficacy among Iranian EFL teachers. System 37 (2009) 700-707.

[19] Schutte, S. N., Malouff, M. J., Hall, E. L., Haggerty, J. D., Cooper, Golden, J. C., \& Dornheim, L. (1998). Developlent and validation of a measure of emotional intelligence. Personality and Individual Differencens, 25, 167-177.
[20] Shao, K. Yu, W.Y. \& Ji, Z.M. (2013) The relationship between EFL students' emotional intelligence and writing achievement, Innovation in Language Learning and Teaching, 7:2, 107-124.

[21] Shirazi, M. A., Nadoushani, S. M. M. (2016). Emotional intelligence as the predictor of pragmatic competence: A closer look at Iranian EFL learners’ politeness strategies. The Reading Matrix: An International Online Journal Volume 16, Number 2, September 2016.

[22] Tok, S., Moral, S. L., \& Tatar, A. (2007). Adaptation of the revised schutte emotional intelligence scale into Turkish and examination of its psychometric properties International Emotional Intelligence and Communication Symposium May 7-9 2007,325-338.

[23] Tosun, M. (2013). On the relationship between emotional intelligence and foreign language skills in ELT, Master's of Art Thesis, T.C. University Of Gaziantep Graduate School Of Educational Sciences Department Of English Language Teaching, Gaziantep.

[24] Valizadeh, M.R (2016). Iranian EFL students' emotional intelligence and autonomy in distance education. English Language Teaching; Vol. 9, No. 10; 2016

[25] Valizadeh, M.R., Alavinia P. (2013). Listening comprehension performance viewed in the light of emotional intelligence and foreign language listening anxiety. English Language Teaching; Vol. 6, No. 12; 2013. 